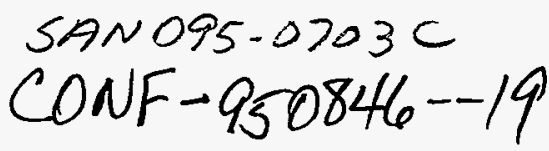

\title{
THE DERIVATION OF MATERIAL PROPERTIES FROM MEASUREMENTS OF RADIATION INDUCED STRESS-TIME HISTORIES
}

\author{
F.W. Davies, D.L. Reeder, D.E. Johnson, L.M. Lee \\ Ktech Corporation, 901 Pennsylvania NE, Albuquerque, NM, 87110
}

\begin{abstract}
Material response experiments using the SATURN soft $\mathrm{x}$-ray source in conjunction with hydrocode modelling have been used to determine equation-of-state parameters for aluminum. In these experiments, stresswaves in irradiated targets have been measured using both quartz and PVDF piezoelectric stress gauges for a wide range of incident fluences. The induced stress profiles are sensitive functions of: (1) the deposition profiles in the target material, (2) the temporal history of the radiation source, and (3) the target material properties. Analysis of the experimental data has shown that observed changes in the shape of the induced stresswave as fluence is varied can be directly correlated to phase transitions. The unique combination of $\mathrm{x}$-ray energy and irradiation time allow phenomena important for determining equation-of-state parameters to be studied separately. By temporally separating the development of thermomechanically induced stress from stress induced by material vaporization a very sensitive measurement of vaporization energy is possible.
\end{abstract}

\section{INTRODUCTION}

The measurement of stress time histories in materials irradiated with short duration intense pulses of $x$-rays and other penetrating radiation has been used as a method to determine material behavior and thermal properties for some time. In current plasma radiating source (PRS) facilities the irradiation times and deposition profiles allow material thermal response phenomena to be studied separately in a single experiment. The effects of material vaporization are separated in time from stress due to thermomechanical response (Gruneisen effects). Studying these effects separately provides an opportunity to assess both parts of the equation of state for a material. In this case a very sensitive measure of the vaporization energy for the material is available.

\section{EXPERIMENT DESCRIPTION}

Results from experiments in the Saturn PRS facility were used with a modified version of the WONDY $V$ computer program to study the vaporization energy for aluminum. Figure 1 shows the experimental configuration in which an aluminum 6061-T6 sample was bonded to a quartz piezoelectric stress gauge. The

This work was supoorted by the United States Department of Energy under Coniract DE-AC?4-94AL850!20. experiment was sized to generate uniaxial strain configuration for the duration of the measurements. Stress data from the quartz gauge mounted on a 950$\mu \mathrm{m}$ thick aluminum 6061-T6 sample which was exposed to $\sim 5.6 \mathrm{cal} / \mathrm{cm}^{2}$ of the output from an argon source are shown in Fig. 2. The initial peak results from a purely thermomechanical response (Gruneisen stress) prior to melt or vaporization of the material. The smaller second peak results from material vaporization.

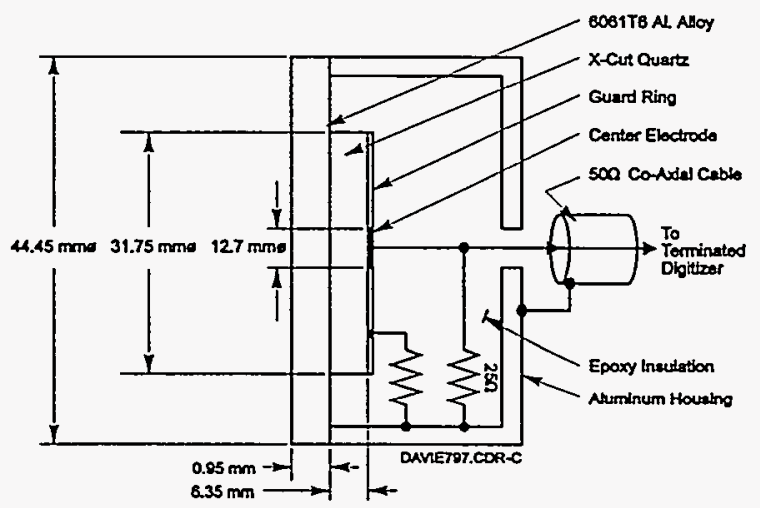

FIGURE 1. Shunted Quartz gauge configuration used to examine response of 6061-T6 aluminum. 


\section{DISCLAIMER}

Portions of this document may be illegible in electronic image products. Images are produced from the best available original document. 


\section{RESULTS}

In Fig. 3, the flux and fiuence time histories for the Saturn X-rays are shown with the energy deposition profile in aluminum. The deposition depth has been divided by the speed of a relief wave in aluminum. The time for the heated depth to be stress relieved by rarefaction waves from the front surface is quite small relative to the irradiation time. The short time required to relieve the heated material makes the peak stress markedly dependent on the details of the flux history.

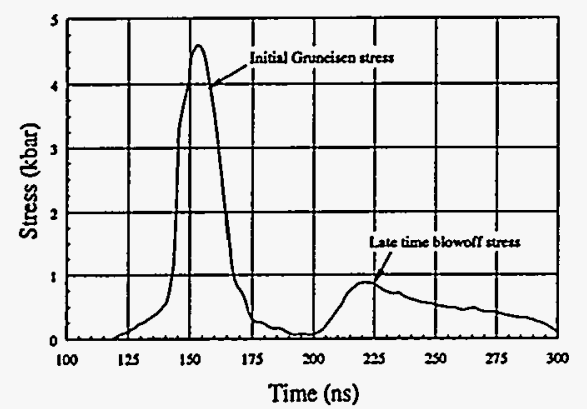

FIGURE 2. Stress history from Al6061 irradiated in Saturn.

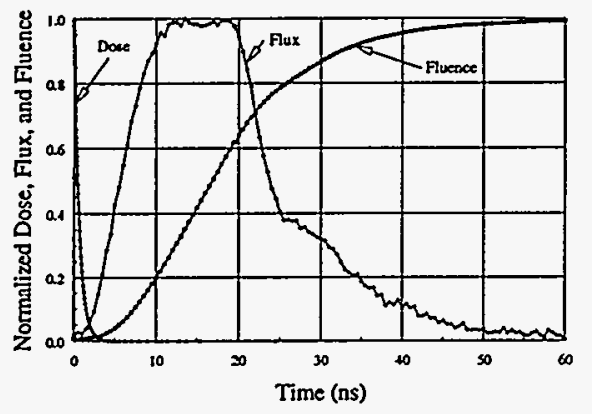

FIGURE 3. Flux and fluence histories for Satum PRS source with deposition relief time.

The version of WONDY used for this analysis was modified to allow an arbitrary radiation flux history to be input. This change was necessary because of the dependence of the induced stress profile on the flux history. The WONDY program was used to model this experiment to gain a better understanding of the phenomena interactions occurring and to derive effective materials property data. Measured flux histories were used as input to these calculations.
The early time stress development and stress wave propagation can be seen in Fig. 4. The legend of this figure gives the time in nanoseconds of each stress profile. The peak stress is developed by about $7.5 \mathrm{~ns}$ at which time only about 12 percent of the fluence has been delivered. The front surface begins to melt at $5 \mathrm{~ns}$ and at $7.5 \mathrm{~ns}$ the melt front extends to $\sim \mu \mathrm{m}$. The melt front does not catch up with the stress wave moving into the material. At $\sim 21 \mathrm{~ns}$ the front surface begins to vaporize and significant blow off induced stress is developed by 24 ns (Fig. 5).

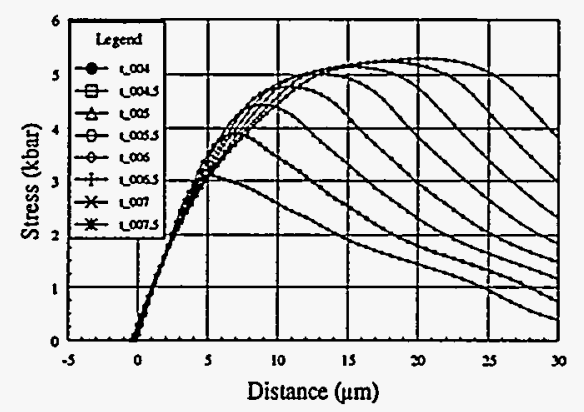

FIGURE 4. Early time development of stress near front surface.

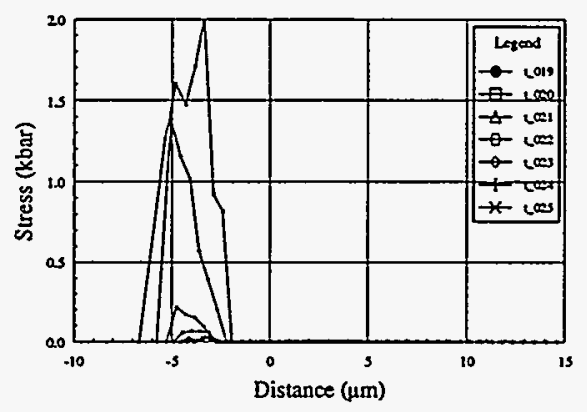

FIGURE 5. Development of stress at front surface due to vaporization.

The vaporization and blowoff continue for the duration of the irradiation. The melt front is $\sim 16 \mu \mathrm{m}$ deep in the aluminum at the end of irradiation so the compressive blowoff stress must propagate across the molten material into the solid. In Fig. 6, the vaporization induced stress pulse is shown shortly after the irradiation ended. The timing and magnitude of this stress pulse can be modified in the WONDY analysis by varying the material vaporization energy. 


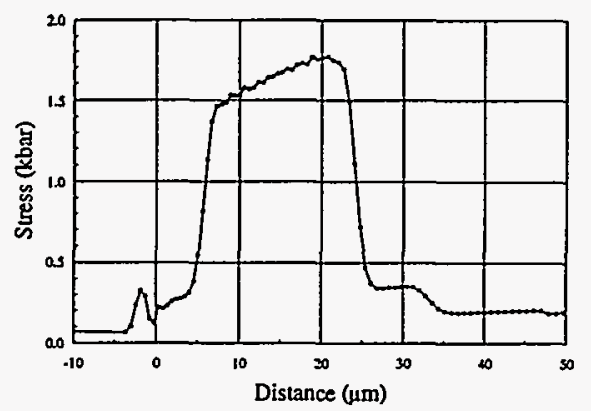

FIGURE 6. Stress wave from blowoff after irradiation terminates.

This sensitivity is shown in Fig. 7 where the legend defines the vaporization energy (cal/gm) used in the Mie Grineisen equation of state description of the aluminum alloy. As expected the initial peak (Grineisen stress) is unaffected by changes in vaporization energy. The second peak is very sensitive, particularly since the difference in vaporization energy for the curves shown in Fig. 7 is only $4.8 \mathrm{cal} / \mathrm{g}$. Comparison of the calculations with the measured results allows the vaporization energy to be defined by matching the predicted and measured second stress pulse. A vaporization energy of 3067 $\mathrm{cal} / \mathrm{g}$ for 6061-T6 aluminum is deduced by matching the amplitude of the predicted and measured stress. As shown in Fig. 8 , the shape and timing of the second peak do not agree well with the data.

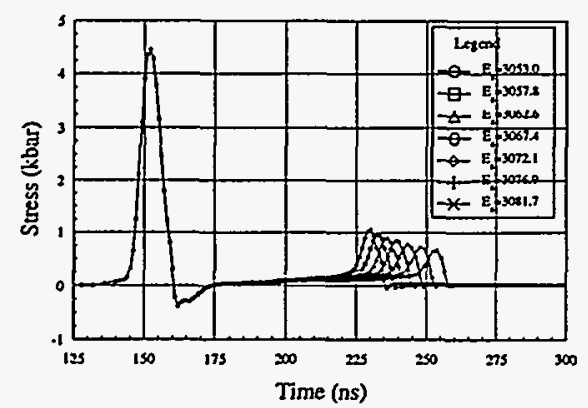

FIGURE 7. Sensitivity of calculated stress to material vaporization energy.
More detailed analysis of the calculated results indicate that deficiencies in the representation of liquid behavior in the WONDY $V$ equation of state affected the results. The analyses need to be performed with a more realistic equation-of-state for liquids to accurately capture the stress pulse resulting from late time blowoff. We are currently working to make the ANEOS package work in WONDY $V$ to support these analyses.

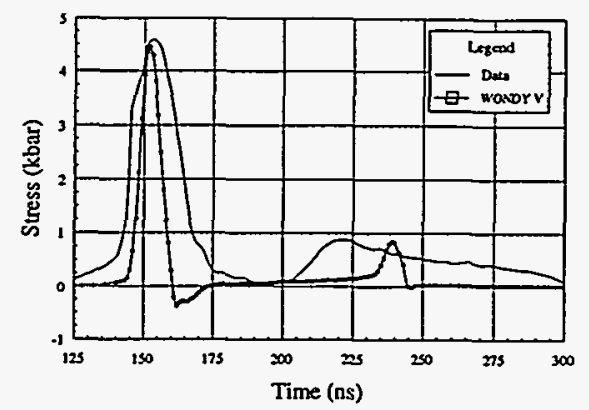

FIGURE 8. Data with WONDY V calculation showing both stress peaks.

However the present analyses do demonstrate that experiments using short duration soft $\mathrm{x}$-rays can provide a sensitive measure of the vaporization energy, a critical equation of state parameter. Furthermore, the potential for examining the behavior of melted materials exists.

\section{DISCLAIMER}

This report was prepared as an account of work sponsored by an agency of the United States Government. Neither the United States Government nor any agency thereof, nor any of their employees, makes any warranty, express or implied, or assumes any legal liability or responsibility for the accuracy, completeness, or usefulness of any information, apparatus, product, or process disclosed, or represents that its use would not infringe privately owned rights. Reference herein to any specific commercial product, process, or service by trade name, trademark, manufacturer, or otherwise does not necessarily constitute or imply its endorsement, recommendation, or favoring by the United States Government or any agency thereof. The views and opinions of authors expressed herein do not necessarily state or reflect those of the United States Government or any agency thereof. 